University of Wollongong

Research Online

Faculty of Law, Humanities and the Arts Papers (Archive)

Faculty of Arts, Social Sciences \& Humanities

$1-1-2015$

It's like going to a cemetery and lighting a candle: Aboriginal Australians, sorry business and social media

Bronwyn Carlson

University of Wollongong, bcarlson@uow.edu.au

Ryan Frazer

University of Wollongong, rfrazer@uow.edu.au

Follow this and additional works at: https://ro.uow.edu.au/lhapapers

Part of the Arts and Humanities Commons, and the Law Commons

Research Online is the open access institutional repository for the University of Wollongong. For further information contact the UOW Library: research-pubs@uow.edu.au 


\title{
It's like going to a cemetery and lighting a candle: Aboriginal Australians, sorry business and social media
}

\begin{abstract}
Death and funeral practices are a constant presence in many Aboriginal Australians' lives - research in some communities found they are eight times more likely to have attended a funeral in the previous 2 years than non- Aboriginal people. This can be explained by two major factors: inordinately high rates of Aboriginal mortality and cultural practices around death (broadly referred to as Sorry Business). Research in other contexts has found traditions once reserved solely for face- to- face interactions are now also taking place online on social media. This paper draws from interviews conducted with Aboriginal social media users from New South Wales, Queensland, South Australia and Western Australia to explore new cultural expressions of Sorry Business. Drawing from Indigenous standpoint theory as both an entry point for inquiry and a tool for analysis, this paper demonstrates that Aboriginal people participate in a diverse range of online practices related to Sorry Business, including notifi cations of deaths and funerals, offering condolences and extending support, and grieving and healing.
\end{abstract}

\section{Keywords}

australians, sorry, business, social, going, media, cemetery, lighting, candle, like, aboriginal

\section{Disciplines}

Arts and Humanities | Law

\section{Publication Details}

Carlson, B. \& Frazer, R. (2015). It's like going to a cemetery and lighting a candle: Aboriginal Australians, sorry business and social media. AlterNative: an international journal of indigenous peoples, 11 (3), 211-224. 


\title{
“IT'S LIKE GOING TO A CEMETERY AND LIGHTING A CANDLE"
}

\section{Aboriginal Australians, Sorry Business and social media}

\author{
Bronwyn Carlson* \\ Ryan Frazer ${ }^{+}$
}

\begin{abstract}
Death and funeral practices are a constant presence in many Aboriginal Australians' livesresearch in some communities found they are eight times more likely to have attended a funeral in the previous 2 years than non-Aboriginal people. This can be explained by two major factors: inordinately high rates of Aboriginal mortality and cultural practices around death (broadly referred to as Sorry Business). Research in other contexts has found traditions once reserved solely for face-to-face interactions are now also taking place online on social media. This paper draws from interviews conducted with Aboriginal social media users from New South Wales, Queensland, South Australia and Western Australia to explore new cultural expressions of Sorry Business. Drawing from Indigenous standpoint theory as both an entry point for inquiry and a tool for analysis, this paper demonstrates that Aboriginal people participate in a diverse range of online practices related to Sorry Business, including notifications of deaths and funerals, offering condolences and extending support, and grieving and healing.
\end{abstract}

\section{Keywords}

Aboriginal, Indigenous, social networking, social media, Sorry Business, death

* Associate Professor, Indigenous Studies, University of Wollongong, Wollongong, New South Wales, Australia. Email: bcarlson@uow.edu.au

$\dagger$ Research Fellow, Indigenous Studies, University of Wollongong, Wollongong, New South Wales, Australia. 


\section{Introduction}

Social media is used widely by Aboriginal people across Australia. Recent research suggests that Aboriginal people, who are enthusiastic users of mobile technology, are accessing social media at a higher rate than other Australians (Callinan, 2014). In addition to the manifold uses these technologies have for all users, for Aboriginal people social media is also providing an additional, very specific function in relation to cultural practices associated with death (Carlson, 2014a). This paper will focus specifically on the ways in which Aboriginal people use the popular social media site Facebook for "Sorry Business" - a term used by Aboriginal people across Australia to describe a broad range of practices associated with death, dying and funerals.

This is indicative of a broader trend, where all across the globe Indigenous traditions once reserved solely for face-to-face interactions are now also taking place on social media sites such as Facebook. Research conducted by O'Carroll (2013a, 2013b) on Māori cultural practices and social media found that Māori are utilizing social media platforms to participate in a range of cultural activities, including using the online video-conferencing service Skype to be "present" at funerals when physical attendance is not possible. Similarly, Molyneaux et al. (2014) found that First Nations communities in Canada are avid social media users. For these groups, vast distances often isolate communities and their members. In response, these communities are increasingly participating in cultural practices online.

In the Australian context, Kral's (2011, p. 5) research reports that Aboriginal youth are using social media to participate in a range of cultural activities. Likewise, Edmonds et al.'s (2012) study of Aboriginal youth's use of mobile devices and social media found that Aboriginal youth used social media for "maintaining connections and for pathways to assist them when facing big decisions" (p. 12). Social media offered these users a sense of community that could provide support in stressful situations. Carlson (2013, 2014a, 2014b) also found that Aboriginal people are participating in myriad activities on Facebook, including cultural practices, maintaining relationships and participating in community politics. Collectively, this research disrupts the dominant but mistaken representations of Indigenous people as parochial Luddites.

When a death occurs, social media is providing Aboriginal people new options for publicly expressing and sharing grief with family, extended social networks and in particular those who are separated by distance. Bereavement is a particularly important cultural practice for Aboriginal people (see Bachelor, 2001; Glaskin, Tonkinson, Musharbash, \& Burbank, 2008). Commemorative practices, such as visits to graves and memorials, provide avenues to maintain an ongoing relationship with loved ones, while mitigating feelings of loss. People visit graves and memorials out of a sense of cultural obligation and respect. These practices are used to maintain a sense of personal relationship with the deceased and to seek solace from grief (Bachelor, 2001, pp. 44-45). For many Aboriginal people who are unable to visit the graves of loved ones, social media presents an alternative option. By providing a space for online memorial sites that are like going to "the cemetery", social media offers a new focal point for grief.

Whilst there are growing bodies of research examining death and commemorative practices online (see Brubaker \& Haynes, 2011) and social networking sites (see DeGroot, 2012; Rossetto, Lannutti, \& Strauman, 2014), there is a paucity of research focusing specifically on Aboriginal people's use of social media for death and funeral practices. In this article, we draw from extensive interview data to explore some of the emerging practices associated with death and mourning made possible by social media. The research findings demonstrate that social media is impacting on Aboriginal cultural 
practices associated with death and dying. The findings also highlight points of tension within Aboriginal communities as public expressions of Sorry Business appear on social media sites and begin to transform the norms of what is and is not culturally acceptable.

\section{Background}

Death and funeral practices are a constant presence in many Aboriginal people's lives-much more so than for non-Aboriginal Australians. This can be explained by two major factors: high rates of Aboriginal mortality and cultural practices around death.

\section{High rates of mortality}

In many Aboriginal communities, Tonkinson (2008) explains, "deaths occur with bewildering frequency" (p. 38). Data from the Australian Bureau of Statistics (ABS, 2010b) shows an appalling discrepancy between the life expectancies of Aboriginal and non-Aboriginal Australians. As at 2010, Aboriginal males live for an average 11.5 fewer years than nonAboriginal males (67.2 years and 78.7 years respectively); the difference is 9.7 years for females (72.9 years and 82.6 years respectively). And while for non-Aboriginal Australians death is reserved almost exclusively for older age groups, the deaths of Aboriginal people are spread more evenly across age groups. In the 35-44-year-old age group, for instance, the combined Aboriginal populations of South Australia, Western Australia and the Northern Territory (areas of Australia with high Aboriginal populations per capita-many living in rural and remote areas) experience death rates seven times higher than non-Aboriginal people across the same regions. Infant mortality is also much more common. Aboriginal populations in the Northern Territory, for example, experience rates over three times that of non-Aboriginal Australians (13.6 deaths per 1,000 live births compared with 3.8 deaths per 1,000 live births respectively). Suicides are likewise more commonplace-approximated to be around 40 percent higher than the rate of non-Aboriginal suicide (Carlson, 2014b).

The reasons for these differences are complicated. They parallel patterns of inequality experienced by Indigenous peoples globally. Inequalities in education, access to health services, social marginalization and stress (Burbank, 2011)_caused and compounded by ongoing colonial legacies-contribute significantly. And while Burbank, Glaskin, Musharbash, and Tonkinson (2008) emphasize that premature and preventable mortality of Aboriginal people is "found whether one is looking at urban, rural or remote Indigenous communities" (p. 1), health outcomes for Aboriginal people vary considerably across the country. Clear inequalities are evident between those living in major cities (about 32 percent of Aboriginal people) and those living in regional (43 percent) and remote areas (25 percent) (ABS, 2010a). These latter areas outside of major urban and rural centres often experience ramified inequalities, exacerbated by factors such as severely under-resourced (or even entirely absent) health services. These communities uniformly experience the worst health outcomes of all Australian demographic groups.

\section{Sorry Business}

Statistics partially explain the more prominent position of death and funeral practices in the lives of Aboriginal people. However, distinct cultural practices and obligations around death and extended Aboriginal kinship networks contribute greatly to the everyday prominence of death. Sorry Business-the myriad cultural practices around death and loss-is a much-documented phenomenon in anthropology (see Glaskin et al., 2008). Beliefs and ceremonies associated with death are diverse across Aboriginal Australia. They may involve lengthy ceremonies lasting several days with 
strict protocols around language, names, images and personal possessions. Alternatively, death might be marked by funerals that include images, speaking the deceased's name and choreographed performances (Carlson, 2014a). In some instances, behaviours that contravene strict cultural protocols in one community can be entirely acceptable in another.

Although these practices differ considerably across Aboriginal groups and communities, Anderson et al. (2012) found that, by and large, "there is less of a cultural obligation on nonAboriginal people to attend funerals than for Aboriginal people" (p. 26). Glaskin et al. (2008) explain that living a thousand kilometres from the deceased, for example, "does not constitute a sufficient impediment to attending a kinsperson's funeral" (p. 5). The absence of certain family members from a funeral, as Patel (2014) explains, "can bring shame to the extended family and other members within the kinship system" (p. 79). It may even constitute the breaking of the community's law, and absentees can face punishment (Anderson et al., 2012, p. 26). And because of the strong, extended kinship networks of Aboriginal communities, Aboriginal people generally have these responsibilities towards great numbers of kin.

Unsurprisingly then, a recent study by Anderson et al. (2012) found Aboriginal people attend many more funerals than non-Aboriginal people. They found Aboriginal people were eight times more likely to have attended a funeral in the previous 2 years. Over half of the study's Aboriginal respondents indicated they had attended seven or more within the previous 2 years, and one-third had attended between 12 and 30 funerals in the same period. Similarly, an earlier study by Hanson (2005) included Aboriginal people who were attending up to several funerals a week. Aboriginal people also start attending funerals at a much younger age. Anderson et al. (2012) found the rate was 95 percent for Aboriginal respondents aged 15 or younger, compared with 47 percent for non-Aboriginal people.
The prominence of Sorry Business has a great impact on the lives of Aboriginal people. In many communities, Sorry Business overrides all other responsibilities (Musharbash, 2008). Discussing the Martu people of the Western Desert of Western Australia, Tonkinson (2008) found mortuary activities following a death "greatly impinge upon their everyday life" and involve "enormous amounts of time, money and effort-not to mention the debilitating reoccurrence of grief” (p. 38). Likewise, McCoy (2008), while researching Sorry Business in the Kutjungka region of Western Australia, noted the demands of funeral practices can be "physically, financially and emotionally stressful and even exhausting" (p. 66). In a particularly extreme case, the Warlpiri people at Yuendumu in the Northern Territory were spending, on balance, up to 1 in every 3 days of the year engaged in Sorry rituals, which precede funerals in that community (Musharbash, 2008). These ceremonies often involve over a thousand people and span a week or more.

In this paper, we adopt a broad definition of Sorry Business, including all Aboriginal cultural practices relating to loss. We understand culture as fluid and ever changing. Limiting understandings of Sorry Business to only those practices with temporal ties to pre-colonial Australia risks relegating Aboriginal culture to an imagined static past. Further, it imposes an understanding that does not map onto the contemporary reality of myriad practices across vastly different Aboriginal cultural groups. By keeping an open definition-including not only "traditional" practices, such as Sorry Camps (see Musharbash, 2008), but also more recently emerging practices, such as church funerals, grave visitations, and even public expressions of mourning on social media-we avoid some of the problematic aspects of more narrow definitions. 


\section{Social media}

Previous research has shown us that Aboriginal people continually incorporate new expressions of Sorry Business to accommodate changing circumstances in communities. Anthropologists have noted new and creative ways Aboriginal people deal with challenges around funeral practices (see Glaskin et al., 2008). In one study about the resilience of Sorry Business in the Puntu community of Western Australia, McCoy (2008) comments: "Creativity around the expression of sorry business suggests Puntu autonomy but also resistance to the ways that Kartiya [non-Aboriginal people] might prefer to conduct ceremonies around loss and death" (p. 66). Hence, McCoy suggests, practices of Sorry Business can serve to reaffirm cultural identity and sovereignty.

Research also tells us Aboriginal people have always been early adopters of technology, with social media being no exception. Across Australia, Aboriginal use of social media is approximately 20 percent higher than the national average and in remote communities over 60 percent of the population are active Facebook users (Callinan, 2014). Carlson (2013) likewise observed that the use of social media by Aboriginal people has become an "everyday, typical activity" (p. 147). Aboriginal people are actively participating in cultural activities on social media-particularly Facebook (see also Carlson, Farrelly, Frazer, \& Borthwick, in press). This site has become a vehicle not simply for communicating and networking among and between Aboriginal people, but also a tool for sharing different cultural practices, norms and expectations.

However, although both are significant in the lives of Aboriginal people, the relationship between social media and Sorry Business is currently unknown. Initial interviews for this project revealed social media, such as Facebook, had become an important conduit for Aboriginal people to express grief and sorrow, and to find common ground between and among various kinship networks. Participants also expressed serious reservations about the use of social media for these purposes. Subsequent interviews explored this relationship in more detail. This paper reports the project's findings to date.

\section{Methodology}

\section{Indigenous standpoint theory}

The emergence of Indigenous research methodological frameworks has provided a strong source of critique for Western methodological frameworks that have (often knowingly) perpetuated and accentuated the negative impact of colonization for Indigenous peoples globally. Indigenous research methodologies have also given power to Indigenous standpoints that more accurately and sensitively guide research towards diverse, appropriate and valid representations of Indigenous perspectives, voices and experiences (Martin, 2008; Nakata, 2007; Rigney, 1997; Smith, 2012).

This project draws from Indigenous standpoint theory (IST) (see Moreton-Robinson, 2014; Nakata, 2007; Rigney, 1997) as both an entry point for inquiry and a tool for analysis. Influenced by the work of Foucauldian and feminist sociologists, IST is understood as both a discursive construction and a conceptual tool that offers a method of inquiry useful for analysing Indigenous experiences usually "excluded or subjugated within intellectual knowledge production" (Nakata, 2007, p. 213). It is not deterministic of any truth but rather lays open a basis from which to launch a range of possible arguments for a range of possible purposes. IST provides a point of admission for Indigenous researchers "to explore the actualities of the everyday and discover how to express them conceptually from within that experience, rather than deploy predetermined concepts and categories for explaining experience" (p. 214). In this way, it is a political and decolonizing form of analysis. 
In relying on Indigenous experience and Indigenous knowledges as its starting point for analysis, IST departs from many approaches to sociological understandings of social and cultural realities. It puts emphasis on experience rather than theory. However, IST does not marginalize theory in any way; on the contrary, it shows us that ideas come from practices, from experience, and from our day-to-day lived realities. And it shows that these realities are sometimes better understood through Indigenous knowledge systems-alongside, where appropriate, theoretical standpoints located in Western epistemologies.

Nakata (2007) maps out three fundamental principles for an IST. The first involves understanding that the researcher is "discursively constituted within and constitutive of complex sets of social relations as expressed through the social organisation of ... [the] everyday" (p. 216). Second, that, as a researcher, one must recognize "Indigenous agency as framed within the limits and possibilities" (p. 216) of what can and cannot be known from this constituted position. The third principle is an incorporation of the "tensions" (p. 216)—or what he refers to as the constant "tug-of-war" - that inform as well as limit what can be said or known. These tensions are points of emergence and becoming, where Indigenous knowers (re) shape their engagements with the world. These engagements do not necessarily seek or reflect an underlying unity in the everyday, but rather provide evidence of the contradictions and ambiguities of discursively and materially constituted Indigenous spaces.

IST is complemented by and perhaps best understood alongside Nakata's concept of the Cultural Interface- - a term he coined to denote the everyday site of struggle that continues to confine colonized people. For Nakata, the Cultural Interface represents a site of interaction, negotiation and resistance, whereby the specificities of the everyday articulations of Indigenous people can be understood as both productive and limiting. The Cultural Interface disrupts the intelligibility of mainstream academic thought that situates experiences and representations of experiences of Indigenous Australians uni-linearly and simplistically as cause/effect, us/them, centre/other, white/black and so forth. It helps us as researchers to see that:

there are spaces where people operate on a daily basis making choices according to the particular constraints and possibilities of the moment. People act in these spaces, drawing on their own understandings of what is emerging all around them ... in this process people are constantly producing new ways of understanding and at the same time filtering out elements of all those ways of understanding that prevents them from making sense at a particular point in time and trying in the process to preserve a particular sense of self. (Nakata, 2007, p. 201)

The Cultural Interface makes problematic the space of everyday Indigenous negotiations without applying limitations singularly to the canonical lens, and enables us to arrive as researchers knowing already that limits are discursively placed.

IST and the Cultural Interface are particularly suitable for this project for a number of reasons. First, IST offers an entry point for researchers to explore the experiences of Aboriginal users of social media through the lens of specific cultural knowledges of death and related ritual practices. Articulations of this experience can then be collated and understood, or theorized, according to Aboriginal epistemes; that is to say, according to knowledge that has accrued both around the survival of Aboriginal people for tens of thousands of years and since the brief and devastating period of colonial rule. In this way, data from Facebook and other forms of social media can be evaluated for their language and content at the level of culture, and various approaches to Sorry Business can be understood according to a particular user's or group's 
kinship relations and cultural mores. IST allows Indigenous researchers to extrapolate from the data collected a sense of the specific cultural landscape that might inform users' dialogue, what the user says, and how s/he chooses to express issues pertaining to death and loss.

As for the Cultural Interface, this model provides a gateway for researchers to understand how Indigenous people deploy certain tools-this instance, social media-to find productive ways to counter colonial hegemony. The Cultural Interface is a space where agency can be effected, where change can occur, where Indigenous people can "make decisions". As both a symbolic and material site of struggle, the Cultural Interface allows the exploration of everyday Indigenous experience.

\section{Research design}

To explore the diversity of everyday experiences of Aboriginal social media users, data were collected through a variety of qualitative methods. Following formal ethics approval from the University of Wollongong's ethics committee, participants were recruited through contacting key figures from each community, who were thereafter employed as one-off research assistants. This method was determined both ethical and effective. Respected persons in communities could communicate the purpose and content of the research project to potential participants and help interviewers conduct the interviews in an appropriate manner. In this way, informed consent was ensured. In total, eight different communities across New South Wales, Queensland, South Australia and Western Australia participated in the project. These communities represented a broad crosssection: from cities (Sydney, Brisbane, Adelaide, Perth), regional areas (Illawarra, Batemans Bay, Broome), and remote communities. Participants came from a wide variety of ages (18-60 years of age) and backgrounds: political activists, university students, stay-at-home parents, community Elders. To ensure anonymity, participants were given a pseudonym. Fifty semi-structured interviews were conducted, lasting between 30 and 90 minutes each. Ten themes were covered in the interviews, including quantity and quality of social media use; expressions and concerns of culture on social media; Indigenous identities; and community formation and concerns. Drawing on Nakata's (2007) IST and Cultural Interface, interview transcripts were then subject to a form of narrative discourse analysis.

As social interactions are increasingly conducted on social media, there was also an opportunity to collect additional data through an online social media-driven survey created using SurveyMonkey and promoted via Facebook and Twitter, using a snowball sampling technique. The survey was anonymous and consent was tacit, indicated by the choice to complete the survey. Simple quantitative analyses were conducted using SurveyMonkey's inbuilt statistical tools. Methodological rigour was ensured through research triangulation: using a multi-method approach and ensuring all analysis was conducted by at least two researchers.

\section{Results}

Participants described a diverse range of online practices related to Sorry Business. They have here been grouped into three themes: (1) notifications of deaths and funerals, (2) offering condolences and extending support, and (3) grieving and healing. Participants raised several concerns about using Facebook for Sorry Business. These issues highlight the contested nature of online spaces, where cultural practices, values and understandings clash and coalesce in this online Cultural Interface. Here, the day-to-day struggles between Aboriginal people and colonial rule present opportunities for challenge and for change. Users engaged with social media to express cultural practices 
and values around death in new and dynamic ways. In this way, our results align with Tonkinson's (2008) work on Martu people's funeral practices. She showed that despite sometimes placing heavy burdens on individuals and communities (in terms of time, money and emotional costs), practices of Sorry Business can also serve to affirm cultural identity and "demonstrate cultural dynamism, innovation and creativity" (p. 37). And in the current study, this is through engaging with new social technologies and producing new forms of cultural expression.

\section{Notification of deaths and funerals}

Participants were asked if and how Aboriginal people were using social media for Sorry Business. They confirmed that social media is a forum where cultural practices around death are active. A majority of participants stated that they used Facebook to notify friends and family of deaths and funerals. Aboriginal communities are often spread across vast distances, making communication and the organization of Sorry Business difficult. Facebook offers the opportunity to notify huge networks of people instantly and simultaneously, giving them time to prepare for any subsequent Sorry Business. Participants stated:

A lot of them are, they're letting family know someone's passed away. There's a lot of Sorry Business and stuff that does show up on Facebook. (Rachel, female, 22)

Like who dies now, through Facebook. Family members who have passed away. Then you get a phone call, "Oh, such and such has passed away.” (Melanie, female, 30)

However, the practice of notifying friends and family of deaths through social media was often problematic. Participants articulated two main issues: a lack of cultural protocols around social media notifications of a death and the posting of names and images of the deceased. First, it was sometimes considered inappropriate and disrespectful to notify family of a person's death through social media sites such as Facebook. This caused some participants great distress. For instance, one participant described a woman who had married into an Aboriginal family and notified her online networks of her husband's death. This was seen as greatly disrespectful by the husband's family. The participant explained:

There was an incident a few years back. My Aunty's cousin passed away, and the in-laws put a notice that he'd passed away on Facebook. And my mum and her mum's generation, they wouldn't have known what Facebook was, it wasn't around back then. And that's rude and disrespectful for them doing that. Whereas I think she was being respectful in her head, saying "I'm sorry". But putting that on Facebook. She was married [into the family], so it was different. (Melanie, female, 30)

What is posted on social media is not void of offline ramifications if family and community members consider it inappropriate. Social media is not a disembodied space-it is composed of communities generated by real bodies that interact and communicate with one another (Lumby, 2010; Petray, 2013). Social media offers actual connections between people, facilitating interaction and correspondence offline (Joinson, 2008; Petray, 2013). As Taylor and Spencer (2004, p. 237) argue in reference to online communities, "This new world lies alongside our everyday experiences." What is posted on social media is still very much subject to community scrutiny and regulations much in the same way as face-to-face interactions. This was noted here by the same participant:

Yeah, and in the family, no one spoke for ages. They were all walking around on eggshells at his funeral. I think she got spoken to, asked 
to apologise and remove what she'd posted. (Melanie, female, 30)

The above story reveals the tensions that can arise when incongruous cultural values meet online-not just between Aboriginal and nonAboriginal people, but also across generations. Complex and contrasting norms and discourses of respect come into contact, leading to serious offline effects. Similarly, the issue around naming and image taboos can result in conflict and disagreement. Two participants commented that:

It's an unwritten rule [to not use a deceased person's name]. It's an unwritten rule, but in general Aboriginal people, you get told not to mention it. Like, because I've got two names. One name's [A] and the other's [B], and I was named [A] after a bloke. My Dad named me. But as soon as he passed away no one called me [A], they called me [B]. And not until a couple of years later did they start calling me [A]. So like we grow up with knowing that. When someone passes away, if their name is ... you say, "Oh yeah, he passed away." You got to know who they are, try and put the dots together as to who passed away. Like we grow up learning that. But like when you're given a Facebook where you can write whatever and the whole world's going to know, that's the misuse. You know, sometimes it's just a misunderstanding or by accident. But especially Facebook, like you find out people who die through Facebook. (Rachel, female, 22)

And now they [young Aboriginal people] actually put photos on Facebook. Which I think is wrong. I don't agree with it. (Laura, female, 30)

Several participants said these image and naming taboos are becoming increasingly irrelevant—something less important to the younger generations. Tonkinson (2008), in her work on the Martu people, also found that "this taboo has now been relaxed" (p. 45). The participant below supports this claim.

For the younger generation, Facebook, they've grown up with it. They don't see the big deal. See we've, I'm part of both worlds. I just wouldn't post anything because I don't know, it may offend someone, it may not. Whereas young generation, in their heads, they like, "It's not offensive." And the older generation is like, "Yes, it is very offensive!" (Laura, female, 30)

The above accounts demonstrate that when it comes to practising Sorry Business, social media can be a problematic space for Aboriginal people. Competing cultural values and practicesboth Aboriginal and non-Aboriginal-come into contact and compete and combine. That incompatible cultural values around online expressions of Sorry Business has potential to result in conflict between different generations of Aboriginal people is a novel research finding. While the scope of this particular project's data set did not allow a more in-depth analysis, this subject warrants further investigation.

However, while sometimes limiting or problematic, these online spaces are also productive. Participants are reproducing cultural practices of Sorry Business in original ways, afforded by the proliferation of new social technologies, as noted by this participant:

Well, what is culturally important to us? Over here in WA [Western Australia], or my group, you say, well, it's about the funerals. So when people pass on-the Sorry Business. And that is massively communicated over social media. So people know where to go and who's passed on and what's happening. So that's definitely a big cultural thing. (Sam, male, 35)

The above participant went on to describe the deep cultural importance of funerals for his community in the Pilbara. He lives and works in Perth, around 1,500 kilometres from the 
Pilbara. Through Facebook, his community is able to instantly communicate the death of a person across Australia, giving them time to organize transport and any necessary ceremony. He went on to explain:

So one of the big events that we have up in the Pilbara, for example, funerals are really, really important. And if you don't go to that funeral, well culturally, it's going to be a really bad thing. So being able to communicate across family members that someone has died and there's a funeral that's happening and where it is and where it's at, and the cultural things that are happening around that. That happens a lot through social media. (Sam, male, 35)

As this participant demonstrated, the deep importance of Sorry Business for his community is bolstered by their engagement with Facebook. It allows them to avoid the "really bad thing" of disengaging with Sorry Business. While moving geographically far from the community, contact and culture is continued online.

\section{Offering condolences and extending support}

Many participants described using social media to offer condolences to grieving family. These messages of support were often extended indirectly through "status updates" on Facebook. This was understood as an act of respect, particularly if done in a general way through not directly naming the deceased-as one participant from a remote South Australian community said, this is often just saying something simple like "Thinking of you" to the family of the deceased. Participants explained that:

... people will offer their condolences, you know. And somebody might write a status, and somebody will comment underneath. But people also write their own status, like, "Just want to say sorry to such and such family." (Laura, female, 30)
... because family live so far from each other, they'll send a message, "Send my condolences", you know? But like then I post, "I'm thinking of so and so family." (Daniel, male, 20)

One participant from a remote South Australian community suggested that sending condolences through Facebook could even be used as a substitute if a friend or family member lived far away and was not able to make the funeral:

People put up a status of sympathy to the family. If they can't make the funeral, they will say sorry on Facebook. (Danielle, female, 30)

In her work with the Martu people, Tonkinson (2008) noted how "the salience of relationships, both distant and close, is sharply demonstrated among Martu in their responses to death" (p. 37). The above accounts-though from participants of different Aboriginal nationsparallel her findings. Participants in this study used social media to enact practices of respect through offering condolences to those who had lost family and friends. Relationships and communities are strengthened and renewed through these acts of support and condolence.

\section{Grieving and healing}

Last, participants described a variety of grieving and healing practices that occur on social media. Many participants shared photos of the deceased with their online networks. This again troubles the idea of any uniform taboo on images across Aboriginal communities. Through sharing photos and stories and messages, deceased kin were "kept alive", as explained by these two participants:

So what we, with my cousin who passed away, we upload photos of them on their [Facebook] pages, if we can't be there, we'll write on their pages. Because that is a way that we keep them alive through that. That's a good thing. (Daniel, male, 20) 
Just to say "Miss you", those sorts of things, and put some photos up of them as well [on Facebook]. (Justine, female, 36)

Another online grieving practice involved commemorating or "maintaining" anniversaries of the deceased's deaths and birthdays. One participant likened this to the act of visiting a cemetery:

Every year on his birthday we look at his [Facebook] page, because you see an influx of new messages, and people will share a story on his anniversary. It's like going to a cemetery and lighting a candle, but you don't go and physically light a candle. (Rose, female, 34)

Yes, I do [see practices of Sorry Business online]. Big time. There's a lot of that. Maintaining anniversaries. Yeah you see that all the time. Every time there is one, each time there is an anniversary, you see that. We all write on those [Facebook] pages, back up those individuals. (Jacquie, female, 25)

So like, there's a young boy that got murdered down south. But like his mum shared these comments, like she writes [Facebook] posts, like sometime his anniversary or anything like, "Oh today I woke up and I seen a bird and it reminded me of my son", you know? So it can be good, it's just how you wanna see, like how you wanna see it. (Rachel, female, 30)

By maintaining anniversaries, opportunities for people to extend support to those grieving are opened. Here, through Facebook, the online and public act of grieving unites community.

In some instances grieving involved participants sending messages to the deceased through Facebook comments and status updates. These were often posted on the deceased's online profile page or a memorial page-sometimes called "Sorry Pages". These online memorials or "virtual cemeteries" (Roberts, 2004) are on the increase on social network sites. Sorry Pages allow for informal and personalized commemorative and memorialization practices. People can visit Sorry Pages and post comments and maintain connections with the deceased. As noted by these two participants:

My niece, who looked up to him, gets depressed every now and then, you know. It's like, she uses that [Sorry] page on Facebook as a means of, she'll write to the page, she'll write on the page, "Oh I love you", or "I miss you, I wish you were here", and this and that. Share her problems that way. (Rose, female, 34)

Sometimes I'll come across some memorial pages. But it's mainly just posts, where someone will just write it in their status, "Been 20 years, brother, I'll miss you forever." And then you'll find all these just love hearts, or just like, "We're thinking of you." There'll be no bad comments in there at all. It'll just be all of us just supporting those people, and feed off each other's support. Yeah, so that happens pretty regularly. (Jacquie, female, 25)

Deceased kin's social media pages become online memorials for friends and family. And as these accounts show, just like offline, the deceased and the living remain connected (via kin relations) and this is often demonstrated through public displays of grief and loss in posts on social media. As noted by Field, Gal-Oz, and Bonanno (2003), the living can maintain relational continuity with the deceased indefinitely. Social media helps people maintain a bond with the deceased (DeGroot, 2012) and the relationship is maintained provided communication continues (Parkes, 1998).

\section{Discussion}

Death is disproportionately present in the lives of Aboriginal Australians. The causes are well documented. The "gap" between Aboriginal and non-Aboriginal life expectancies evidences 
the ongoing legacy of colonial violence. Sorry Business, the diverse cultural practices following the loss of a loved one, holds immense significance for Aboriginal people and their communities. The collusion of these two phenomena makes death omnipresent.

The participants in this study confirmed this. But their testimony also evidenced the everchanging, creative, productive and adaptive force of Aboriginal cultures. From inner Sydney to remote South Australia, myriad expressions of Sorry Business are now facilitated by fast, expedient technologies. Social media has become a vital tool for making sense of loss.

A deep reading of the participants' accounts unveils the still-present historical violence of colonialism. The fact that Facebook was understood as a substitutive space for funeral attendance, for instance, echoes the historical dispersion of Aboriginal people whose distance from ancestral Country makes physical attendance difficult for a range of reasons, including policies of dispossession and forced removal. The clashing of cultural values around deathbetween Aboriginal and non-Aboriginal people, and between Aboriginal groups themselvesis a direct consequence of colonization. The notion of "support" can be understood as a mechanism of survival where shared sorrow can alleviate the loss experienced by death. IST allows us to see these responses as expressions of experience that always, in every sense, connote a violent, historical backdrop to death and the cultural practices of Sorry Business.

\section{Conclusion}

This paper offers the first in-depth qualitative study of Aboriginal people's use of social media for Sorry Business. Drawing on interview data from Aboriginal people located across diverse communities throughout Australia, it explores the emerging practices associated with death and mourning made possible by social media. These practices-including using Facebook for notifications of deaths and funerals, offering condolences and extending support, and grieving and healing-were shown to be both productive and problematic.

We can extrapolate the following three conclusions from the responses detailed above. First, social media is a complex and contested space for Aboriginal people, where competing understandings, values and performances of respect and bereavement intersect in this online Cultural Interface. It empowers some to fulfil cultural responsibilities across distance, while leading to conflict between families for others. Second, it challenges some still widely held but mistaken notions that Aboriginal cultures are static or anti-technology. Most importantly, however, the paper demonstrates that the complex convergences between Sorry Business and social media are creating new and dynamic forms of cultural expression and connection. It pays testament to Aboriginal people's ceaseless assertion of sovereignty and reinvention of cultural vitality.

\section{Acknowledgments}

The authors wish to acknowledge and thank the Aboriginal people who participated in this study. Your contributions, experiences and anecdotes have enriched this area of research. Additionally, we would also like to thank the research assistants in each community who generously provided us with information on local cultural protocols. This research has ethics approval from the University of Wollongong Human Research Ethics Committee and is supported by the Australian Research Council Discovery (Indigenous). 


\section{References}

Anderson, M., Bilney, J., Bycroft, N., CockatooCollins, D., Creighton, G., Else, J., . . . Moller, J. (2012). Closing the gap: Support for Indigenous loss. Australian Nursing Journal, 19(10), 24-27.

Australian Bureau of Statistics (ABS). (2010a). The bealth and welfare of Australia's Aboriginal and Torres Strait Islander people (cat. no. 4704.0). Canberra, Australia: ABS.

Australian Bureau of Statistics (ABS). (2010b). Measures of Australia's progress 2010 (cat. no. 1370.0). Canberra, Australia: ABS.

Bachelor, P. (2001). Beyond the funeral. Grief Matters: The Australian Journal of Grief and Bereavement, 4(4) 43-46.

Brubaker, J. R., \& Hayes, G. (2011). We will never forget you [online]: An empirical investigation of post-mortem MySpace comments. In Proceedings of the ACM 2011 Conference on Computer Supported Cooperative Work (pp. 123-132). New York, NY: ACM Press.

Burbank, V. (2011). An ethnography of stress: The social determinants of health in Aboriginal Australia. New York, NY: Palgrave Macmillan. Burbank, V., Glaskin, K., Musharbash, Y., \& Tonkinson, M. (2008). Introduction: Indigenous ways of death in Australia. In K. Glaskin, M. Tonkinson, Y. Musharbash, \& V. Burbank (Eds.), Mortality, mourning and mortuary practices in Indigenous Australia (pp. 1-20). Surrey, England: Ashgate.

Callinan, T. (2014). Remote Indigenous Australians rely on Facebook to stay in touch. Retrieved from http://www.sbs.com.au/news/article/ 2014/08/26/remote-indigenous-australians-relyfacebook-stay-touch

Carlson, B. (2013). The "new frontier": Emergent Indigenous identities and social media. In M. Harris, M. Nakata, \& B. Carlson (Eds.), The politics of identity: Emerging Indigeneity (pp. 147-168). Sydney, Australia: University of Technology Sydney E-Press.

Carlson, B. (2014a). Indigenous Australia's diverse memorialisation of the dead. Retrieved from http:// theconversation.com/indigenous-australiasdiverse-memorialisation-of-the-dead-33628

Carlson, B. (2014b). Well-connected Indigenous kids keen to tap new ways to save lives. Retrieved from https://theconversation.com/ well-connected-indigenous-kids-keen-to-tapnew-ways-to-save-lives-30964

Carlson, B., Farrelly, T., Frazer, R., \& Borthwick, F. (in press). Mediating tragedy: Facebook, Aboriginal peoples \& suicide.

DeGroot, J. (2012). Maintaining relational continuity with the deceased on Facebook. Omega, 63(3), 195-212.

Edmonds, F., Rachinger, C., Waycott, J., Morrissey, P., Kelada, O., \& Nordlinger, R. (2012). Keeping intouchable: A community report on the use of mobile phones and social networking by young Aboriginal people in Victoria. Melbourne, Australia: Institute for Broadband-Enabled Society, University of Melbourne.

Field, N. P., Gal-Oz, E., \& Bonanno, G. A. (2003). Continuing bonds and adjustment at 5 years after death of a spouse. Journal of Consulting and Clinical Psychology, 71, 110-117.

Glaskin, K., Tonkinson, M., Musharbash, Y., \& Burbank, V. (2008). Mortality, mourning and mortuary practices in Indigenous Australia. Surrey, England: Ashgate.

Hanson, T. (2005, July). Finding a path to healing. Paper presented at the Seventh International Conference on Grief and Bereavement in Contemporary Society, London, England.

Joinson, A. (2008). “Looking at”, “Looking up” or "Keeping up with" people? Motives and uses of Facebook. Retrieved from http://digitalintelligencetoday.com/downloads/Joinson_Facebook. pdf

Kral, I. (2011). Youth media as cultural practice: Remote Indigenous youth speaking out loud. Australian Aboriginal Studies, 1, 4-16.

Lumby, B. (2010). Cyber-Indigeneity: Urban Indigenous identity on Facebook. Australian Journal of Indigenous Education, 39(Supplement), 68-75.

Martin, K. (2008). Please knock before you enter: Aboriginal regulation of outsiders and the implications for researchers. Brisbane, Australia: Post Pressed.

McCoy, B. (2008). Death and health: The resilience of "Sorry Business" in Kutjungka Region of Western Australia. In K. Glaskin, M. Tonkinson, Y. Musharbash, \& V. Burbank (Eds.), Mortality, mourning and mortuary practices in Indigenous Australia (pp. 55-68). Surrey, England: Ashgate.

Molyneaux, H., O’Donnell, S., Kakekaspan, C., Walmark, B., Budka, P., \& Gibson, K. (2014). Social media in remote First Nation communities. Canadian Journal of Communication, 39, 275-288.

Moreton-Robinson, A. (2014). Towards an Australian 
Indigenous women's standpoint theory. Australian Feminist Studies, 28(78), 331-347.

Musharbash, Y. (2008). Sorry business is Yapa way: Warlpiri mortuary rituals as embodied practice. In K. Glaskin, M. Tonkinson, Y. Musharbash, \& V. Burbank (Eds.), Mortality, mourning and mortuary practices in Indigenous Australia (pp. 21-26). Surrey, England: Ashgate.

Nakata, M. (2007). Disciplining the savages: Savaging the disciplines. Canberra, Australia: Aboriginal Studies Press.

O'Carroll, A. (2013a). An analysis of how rangatahi Māori are using social networking sites. MAI Journal, 2(1), 46-59.

O'Carroll, A. (2013b). Kanohi ki te kanohi-A thing of the past? Examining the notion of "virtual" ahika and the implications for kanohi ki te kanohi. Pimatisiwin: A Journal of Aboriginal and Indigenous Community Health, 11(3), 440-455.

Parkes, C. M. (1998). Recovery from bereavement. Madison, CT: International Universities Press.

Patel, B. (2014). Providing culturally appropriate palliative care. Journal of Pharmacy Practice and Research, 44(3), 78-79.

Petray, T. (2013). Self-writing a movement and contesting Indigeneity: Being an Aboriginal activist on social media. Global Media Journal: Australian Edition, 7(1), 1-20.
Rigney, L. (1997). Internationalization of an Indigenous anticolonial cultural critique of research methodologies: A guide to Indigenist research methodology and its principles. Wicazo Sa Review, 14(2), 109-121.

Roberts, P. (2004). The living and the dead: Community in the virtual cemetery. Omega: Journal of Death and Dying, 49, 57-76.

Rossetto, K., Lannutti, P., \& Strauman, E. (2014). Death on Facebook: Examining the roles of social media communications for the bereaved. Journal of Social and Personal Relationships, 1-21. doi:10.1177/0265407514555272

Smith, L. T. (2012). Decolonizing methodologies: Research and Indigenous peoples (2nd ed.). London, England: Zed Books.

Taylor, G., \& Spencer, S. (Eds.). (2004). Social identities: Multidisciplinary approaches. London, England: Routledge.

Tonkinson, M. (2008). Solidarity in shared loss: Death-related observances among Martu of the Western Desert. In K. Glaskin, M. Tonkinson, Y. Musharbash, \& V. Burbank, (Eds.), Mortality, mourning and mortuary practices in Indigenous Australia (pp. 37-54). Surrey, England: Ashgate. 